\title{
1036. Comparison of the hemodynamic parameters of two external chest compression devices (LUCAS versus AUTOPULSE) in a swine model of ventricular fibrillation
}

\author{
C Pantazopoulos ${ }^{1 *}$, I Floros ${ }^{1}$, A Mega ${ }^{1}$, C Rigas ${ }^{1}$, I Pavleas ${ }^{1}$, P Vernikos ${ }^{1}$, N Archontoulis ${ }^{1}$, D Xanthis ${ }^{1}$, N lacovidou ${ }^{2}$, \\ T Xanthos ${ }^{3}$
}

From ESICM LIVES 2014

Barcelona, Spain. 27 September - 1 October 2014

\section{Introduction}

Given the difficulty of performing efficient CPR compressions, technology has turned to automaticity. LUCAS device has a pneumatically driven piston to compress the heart and uses active decompression suction on the upstroke. AUTOPULSE is a load distributing band compressor, that is mechanically actuated and battery driven. It provides both direct compression and semi-circumferential thoracic compression.

\section{Objectives}

To compare 2 different external chest compression devices (LUCAS and AUTOPULSE) regarding the hemodynamic effects during cardiorespiratory resuscitation.

\section{Methods}

Forty (40) pigs were randomly allocated into 2 groups. Group L (LUCAS), $\mathrm{n}=20$ and Group A (AUTOPULSE), $\mathrm{n}=20$. After anesthesia ventricular fibrillation was induced. Five minutes post cardiac arrest without treatment, resuscitation was initiated. Electrocardiography, intra-arterial pressure (carotid artery) and Swan-Ganz catheter were used to monitor central venous pressure, cardiac output, cardiac index, systemic vascular resistance and pulmonary vascular resistance prior to ventricular fibrillation and during resuscitation in both groups.

\section{Results}

The hemodynamic parameters demonstrated that there is no statistical difference in mean arterial pressure between the 2 devices but there was statistically significant difference $(\mathrm{P}<0.05)$ in the cardiac output with LUCAS generating higher values than AUTOPULSE.

\section{Conclusions}

The mean arterial pressure that is produced by the 2 devices is similar, while the cardiac output produced by LUCAS is higher than AUTOPULSE.

\section{Authors' details \\ ${ }^{1}$ General Hospital of Athens Laiko, Intensive Care Unit, Athens, Greece. ${ }^{2}$ University of Athens, Medical School, Neonatology, Athens, Greece. ${ }^{3}$ University of Athens, Medical School, M.Sc. Programme in Cardiorespiratory Resuscitation, Athens, Greece.}

Published: 26 September 2014

\section{References}

1. Axelsson $C$, et al: Clinical consequences of the introduction of mechanical chest compression in the EMS system for treatment of out-of-hospital cardiac arrest-a pilot study. Resuscitation 2006, 71(1):47-55.

2. Ong ME, et al: Use of an automated, load-distributing band chest compression device for out-of-hospital cardiac arrest resuscitation. JAMA 2006, 295(22):2629-37.

\section{doi:10.1186/2197-425X-2-S1-P83}

Cite this article as: Pantazopoulos et al: 1036. Comparison of the hemodynamic parameters of two external chest compression devices (LUCAS versus AUTOPULSE) in a swine model of ventricular fibrillation. Intensive Care Medicine Experimental 2014 2(Suppl 1):P83. 